\title{
What to expect from the Michel Temer government in the health care area
}

\author{
O que se espera do governo Michel Temer na Área da saúde \\ ELIAS JIRJOSS ILIAS ${ }^{1}$
}

${ }^{1}$ PhD Professor, Department of Surgery, Faculdade de Ciências Médicas da Santa Casa de São Paulo, SP, Brazil

http://dx.doi.org/10.1590/1806-9282.62.08.709

After the Dilma Rousseff government, the question asked by health care and medical education professionals is: what will the Michel Temer government do to improve the area? Some measures are urgent given the chaos in Brazilian health, especially after the interventionist blunders of the previous government, which was characterized primarily by demagogic and dictatorial attitudes, both in medical education and in assistance to those in need.

\section{SUS, the Unified Health System}

Given the economic recession, managing one of the world's largest health systems in the world, which today serves $75 \%$ of the country's population directly, will be a majorly complex challenge for the Michel Temer government. Current Minister of Health Ricardo Barros has already said that, in the medium term, the country can no longer afford rights guaranteed by the Constitution, such as universal access to health. The federal government has to invest at least $13.2 \%$ of its net revenues in health. But what is the trick to secure more money for SUS?

One of the solutions that could be put on the table would be a surcharge of products harmful to health, such as soft drinks and cigarettes, or to eliminate a number of notorious tax exemptions. A study by the Institute of Applied Economic Research (IPEA, in the Portuguese acronym) pointed out that on account of the deduction of health-related expenses in the income tax of individuals and companies, the government fails to collect BRL 16 billion per year.

A proposal presented by the new government to relieve SUS would be to create low-cost health insurance for the poorest sections of the population. Although these plans already exist in other countries, we must wait for more details on its scope before issuing a more accurate opinion. But even in view of the unquestionable underfunding of the sector, health economists argue that it is possible to better spend the current funds, improving the management of services, curbing waste and fraud, and giving priority to prevention and health promotion.

Today, the legalization of health also costs about BRL 7 billion in federal, state, and municipal funds. The actions use the universal law proposed in the Constitution to get drugs and other treatments. The way out is to create protocols for recognized therapies made with the help of serious medical entities committed with good medical practice so that the judiciary could be better informed before issuing an injunction for treatment provision without the slightest scientific basis.

\section{SUPPLEMENTARY INSURANCE}

Due to the economic crisis and unemployment, it is estimated that nearly 2 million people will end 2016 with no health insurance, which means they will have to knock on the door of the already underfunded and scrapped SUS. The country spends little on health, less than the world average, and most of the expenditure comes from the private sector. Out of the total invested of $8.5 \%$ of the Gross Domestic Product (GDP), 4.9\% derive from the private sector, while only $3.6 \%$ come from public funds. The amount paid by consumers for health plans had incredible increases in recent years, mainly due to the incorporation of new technologies and treatments. Today, it is almost impossible to hire an individual health plan. Operators prefer corporate and group plans because they are not subject to restrictions in the increase of monthly fees, as is the case with individual plans. The increase in the value of health plans far above the inflation makes this a very expensive option for many families, causing more queues for SUS care. In this catastrophic scenario, creating popular health plans seems a viable and realistic option. Nevertheless, this requires discussion, especially involving the consumer.

\section{Medical education}

In a recent article, professor Antonio Carlos Lopes addressed this problem very well. Between 1500 and 1999, Brazil created 106 medical schools, most of which with the necessary structure for proper training. The thing is that entrepreneurs of education realized the high demand for openings in medical courses is a gold mine associated with prestige and wealth. Result: in the last 14 years, over 
136 medical schools were created. Today, there are 242 schools, and most do not have minimum conditions to train a good doctor. The government authorized schools in municipalities that do not have even a primary care hospital, and with faculty members whose professorial titles are not sufficient for the position. Many of these schools do not have a teaching hospital. They sign agreements with public or private hospitals, which are not prepared to allow training, and students are often left with assisting physicians unprepared for the task. What is the point of having thousands of doctors, if training is so precarious? In the absence of qualified teachers, appropriate mentoring or well equipped hospitals, it will be impossible to train good professionals. "The reckless authorization of medical degrees penalizes students who, innocently, pay up to BRL 9,000 a month in private institutions for the questionable benefit of poor tuition," says Lopes.

The government's proposal is to increase by $65 \%$ the number of vacancies in medicine until 2017. The problem is that the new courses planned as part of the Mais Médicos Program will accept professors who do not have $\mathrm{MSc}$ or PhD degrees, simply because there is a shortage of such professionals. It will be a matter of blind students being guided by blind, unqualified, lecturers, according to Lopes. Fifty-nine percent (59.2\%) of the medical graduates in São Paulo failed the 2013 edition of the Regional Board of Medicine of São Paulo (Cremesp, in the Portuguese acronym) examination, revealing the poor training given by medical schools without proper structure for medical training. The Temer government should immediately prohibit the opening of new medical schools, and close all the schools that do not have qualified teachers and their own teaching hospitals.

\section{The Mais Médicos Program}

Despite being a good idea, in principle, to bring health care to remote and poor locations, the Mais Médicos Program (literally meaning "more doctors") was designed in haste and took advantage of a troubled political moment, with a clear intention of transferring resources to countries under the rule of a dictatorship. This is shown by the huge amount of Cuban physicians enrolled in the program to the detriment of other nationalities, including Brazilian doctors. The idea that those remote and needy communities had inadequate health care not only due to a lack of medical professionals, but especially due to a lack of minimal structure to provide decent service with laboratory testing, imaging exams, hospital facilities, and multidisciplinary teams, has never been raised. The old-fashioned and poetic view of the socialist barefoot doctor, armed with a prescription slip, stamp, and stethoscope, prevailed as if that was enough to solve the complex health problems of the poor in Brazil. Physicians, even those excellently trained, cannot perform miracles. Health care is offered with the support of equipment, tests, hospital infrastructure, multidisciplinary team etc.

\section{Santas Casas, the "holy houses of mercy"}

The precarious situation of Santas Casas (public hospitals whose name literally means "holy houses") is a major concern in Brazil. These are secular institutions across the country, responsible for much of the medical care provided by SUS. They receive much less than they spend, are always in debt and often badly managed.

These institutions use a SUS fee schedule that has been lagged for over 10 years. Of every BRL 100 spent, the hospital receives only BRL 60 . This is most definitely a public shame. Compensation for health should at least keep pace with inflation. Rogatti, in a recent speech at the Federation of Industries of the State of São Paulo (FIESP, in the Portuguese acronym), mentioned some difficulties faced by Santas Casas, including the lack of money in the health budget, payments that are invoiced only after the completion of procedures, and the need to redefine the ceiling of funds to be transferred to some institutions. Writing off tax debts makes no difference, he explained, because most of the debt is with banks. In this meeting on the situation of Santas Casas held at FIESP, the thought that the health management model is scrapped and needs to be modified as urgently as possible was consensus. "We have no doubt that the budget is not right and we have to change the current bad management," he said.

Since the expenses above are greater than the funds given by the government, these hospitals end up resorting to bank loans with unpayable interest. This leads to the collapse of these secular charities, which are responsible for much of the public medical assistance in the country.

\section{Conclusion}

Therefore, and in light of the problems above, we expect the new government to use good judgment and strive hard to solve health problems in Brazil, abandoning the demagogic and populist solutions of the previous government.

\section{References}

Articles published in the Folha de S.Paulo newspaper, and a lecture on Santas Casas held at the Federação das Indústrias do Estado de São Paulo (FIESP). 